\title{
Ergonomic analysis in cold storage rooms: a study of case
}

\author{
Silva, Hebert Roberto ${ }^{\mathrm{a}}{ }^{*}$ and Araújo, Cleudmar Amaral ${ }^{\mathrm{b}}$ \\ ${ }^{a}$ School of Mechanical Engineering, ICAT, Univesity of Mato Grosso, Rodovia MT 270 \\ (Rondonópolis/Guiratinga), Km 06, Rondonópolis MT, 78.735-901, Brazil. \\ ${ }^{\mathrm{b}}$ Laboratory of Mechanical Projects Professor Henner Alberto Gomide, School of Mechanical Engineering of \\ Federal University of Uberlandia, Joao Naves de Avila Avenue 2160, 38400-089 Uberlandia, MG, Brazil.
}

\begin{abstract}
The human work possess a history and, in this dimension, the man is submitted to the conditions that confer it physical and psychological consequences. The activity of work in the present time imposes adverse labor conditions. The ergonomics is a science that it aims at to study the real activity of the work with sights its transformation. This study it was carried through in a sector of processing of meats in a Agroindustry, with the objective to analyze ergonomically the conditions of work and the possible risks it greets it of the workers. It was verified that in the accomplishment of the activities it had an overload of the musculature of superior members, where if it verified the requirement of repetitive movements during four working hours. Also observed the organization of the work, the position of the employees and way to carry through the activities. With the study we conclude that the ergonomic risks in the sector are related to the position during the accomplishment of the activities, requirement of repetitive movements, e the cold that affects the muscular control, reducing some motor abilities as the dexterity and the force.
\end{abstract}

Keywords: ergonomy, antropometry, injuries for repetitive efforts, related osteomusculares riots to the work, agroindustry

\section{Introduction}

Ergonomics can be defined basically as an adaptation of work to people. In other words interprofessional work is based on a set of science and technology, looking for mutual adjustment between man and his work environment in a comfortable and productive, basically seeking to adapt the work to people. The human being, in many respects can be likened to a machine. And the muscles, bones, tendons and ligaments are the elements that make this machine perform movements. Much of the knowledge of Ergonomics Applied to Work comes from studying the mechanics of the human machine. Engineers have developed studies analyzing the mechanical characteristics of this machine and, therefore, less a series of important concepts in the adaptation of work to people.

Since the beginning of the twentieth century, a series of studies devoted to increasing productivity, created a large arsenal of knowledge about the subtleties of the work, known primarily Time and Methods. With the introduction of ergonomics, there was a time of convergence of concepts, so that a series of rules have been developed and used by known Ergonomics. On this occasion of synergy, perhaps be more correct to call that area of Industrial Engineering and methods and times, indicating that the study and improvement of working methods, having the human being as the main, it is deduced that what would be the time required for the job. This was indeed a reality in the mid-twentieth century [1].

During the qualitative analysis using ergonomic check lists is important because it draws attention to the fact that any ergonomic inspection must have the participation of workers in the definition of "yes" or "no" because she often will tell us about that this factor raised by the check-list only happens a few times a day, and he will tell us when we return to that position to prove the existence of that risk.

\footnotetext{
*Corresponding author. E-mail: hebert@ufmt.br.
} 
Ergonomic Analysis called microscopic involves issues related to manual labor and the working method. In this section, the analysis verifies the worker's posture, his body movements, head and eyes as well as their communication activities with the group. In addition to analysis with use of a checklist you can use the video feature - and the tape of the task area, and then examine aspects of posture and actions.

Rationality operative monitoring of prescriptive rationality. This means when you set goals, plans and goals, you should focus on rationality, assess the real condition of achieving that goal. And do an adequate job considering planning appropriate technology, with minimal overhead, appropriate machinery, proper maintenance of machines and working conditions, raw materials and materials to be handled by humans generate little overhead, and the correct method of hand-sufficient and qualified workforce. Man accepts some overhead, but the line between constructive tension and stress is often difficult to establish.

To [2] the development of repetitive stress injuries are caused by inadequate interaction biomechanical factors, work organization, psychosocial risks, environmental risks, and various factors. Repetitive strain injuries have many complex causes and any one of them will be suffering victim of an infinite variety of subtle factors and influences. The development of repetitive strain injury is multifactorial, it is important to analyze the risk factors involved directly or indirectly.

It is very important to raise awareness of managers and facilitators regarding the adoption of appropriate measures aiming at the organization of work (balance between work and prescribing conditions for its implementation) and the consequences of noncompliance of this assessment on workers, especially when working close to the limit of human tolerance. It is also very important to involve employees in the review meetings of dysfunction, so that they can express the small problems and operational organization of work that cause large overhead, especially those related to poor quality materials / components and those related to maintenance problems. It is still necessary that the SESMT is on constant alert for the various forms of overload problems by organizing the work overtime, shift folds schemes, lunch, work on Saturdays, Sundays and holidays and other disorders.

\section{Case Study: slaughter of pigs in refrigerator}

This makes Refrigerator slaughter pigs in series (housing) to meet the needs of domestic and foreign markets. 4200 pigs are slaughtered each day divided into two shifts of 8.80 hours.

"Slaughterhouse-Fridge" the establishment is equipped with complete facilities and suitable equipment for slaughtering, handling, processing, preparation and conservation of the species of meat market in various forms, successfully complete, rational and perfect, non-edible by-products, and have industrial refrigeration facilities. The raw material for pig slaughter is the Male and Female. This raw material must meet all specifications and compliance of the Ministry of Agriculture.

The purpose of this study is to evaluate the ergonomics and the physical layout of the section of pig slaughtering and cutting of the refrigerator. Therefore, this study used the qualitative and quantitative, and analytical procedures, applying the techniques of direct observation and analysis of measurements on each job.The sample consists of employees of the Chamber of pork cuts in a particular line of production (table leg), where they have as their main working tool knives and perform their activities in standing in front of a conveyor carrying the pieces. The 1st shift is from 4:00 a.m. to 13:20 and the 2 nd round between 14:00 to 22:20, totaling 8:20 a.m. daily work per shift. Employees of the production line are standing all the time, and do gymnastics 4 times a day, the sector itself, and perform the rotation function and pre-set pauses for rest. The assessment of working conditions were made considering the noise level in which the employee was subjected, the level of lighting and temperature levels at which the official of each job was submitted. The noise level was assessed using a sound pressure meter "Dosimeter" Simpson brand and model 897. For testing the device was fixed at an official during his work shift in which it conducted its normal activities during the collection of signals. In this case, we assessed the levels of noise that the employee was exposed to during their work activities within your industry on the production line of tables evaluated. As a matter of reading the dosimeter was set back to the ear of the worker during his daily exposure in the workplace as Annexes 1 and 2, NR-15 - Unhealthy Activities and Operations.

For measurements of light levels and temperature were used light meter mark Sper Scientific model 840022 and a Thermo Hygrometer Instrutherm brand 
model HTR-157, respectively. These measurements were performed with the help of Technical Safety, with readings taken near the line of meat processing. To use the light meter adopted the reading procedure according to NBR 5382 Check Interior illuminance. We then eight readings in the vicinity of tables evaluated and calculated the arithmetic mean. As the evaluation took place in the same physical space of the room and points near Cortes has been reading two measures assessed per table.

When measuring temperature reading was performed using the Thermo Hygrometer and based on Item 29.3.15 Local Meats NR-29 was determined at room temperature for pork cuts. Again we emphasize the location of tables in the same physical space resulting in generally the same values of temperature measured in points.

In parallel, during the boning the leg, shoulder, belly and Making the Leather palette was made up of the employee to check the ergonomic risks of the upper limbs. We analyzed the movements and body position of employees who perform the task. The anthropometric survey of employees of this production line was done within the industry work in a specific room next generation due to the rotation of duties performed by employees, being therefore necessary to measure all employees involved.

To obtain the necessary manpower is used to measure the concessions the extra time included in the normalized value of an operation to compensate the worker for production lost due to fatigue and interruptions such as parades usually provided for special needs. Room To Cut Pork has a value of $11.64 \%$ for concessions obtained as described below.

- Bathroom: 20 minutes;

- Labor Gymnastics:

$\checkmark \quad$ Preparatory: 4 minutes;

$\checkmark \quad$ Compensatory 1:5 minutes;

$\checkmark \quad$ Compensatory 2: 5 minutes;

Total: 19 minutes;

Compensatory 3: 5 minutes;

Rotation: 3 minutes;

Total Bathroom + Labor Gymnastics + Rotation $=42$ minutes $=0.7$ hours;

Employees start work in the first round at 04:00 am and leave at 13:20h, so make up a workload of 8:30 per day. However, they have an interval of 1 hour, which is the time reserved for performing their daily meals. These officials are to finish their meals in a recreation area for the interval to complete the meal.
Before starting the work shift, employees do a warm-up exercises Labor Gymnastics taught by a multiplier of the industry itself. After two hours of work production stops, and usually runs another series of exercises and so on until after the work shift. In addition to these breaks for the implementation of Labor Gymnastics, employees have two breaks a day for rest and personal needs.

During the development of a physical effort, the existence of a break helps prevent injuries by 3 mechanisms:

- During pause, if there is static muscular effort, with the production of lactic acid, will be the normal flow of blood that will "wash out" the muscle lactic acid, preventing possible injury;

- If high repeatability of the same movement, there will be time enough for the tendon back to its natural structure, since they are viscoelastic, and take some time to regain the natural conformation;

- During the break occurs lubrication of the tendons by synovial fluid.

In parallel, during the working day in the line of bones belly, shoulder, ham and ham boning palette employees perform rotation basis every two hours, in order to minimize the physical overload at work.

\section{Results}

In ham boning his workday demonstrates high repeatability of movements, too much activity in the ham boning with shoulder flexion and abduction, elbow flexion and extension, ulnar deviation and flexion of the wrist, a slight flexion of the trunk at certain times on the task and keeps the cervical spine in flexion constant throughout their workday. The task is to develop employees classified as high risk. Should be promoted in rotation tasks perceived as high repeatability. It is important that the rotation is done with another task in which critical movement that exists in low intensity. The first bone in the first function is to separate the meat from the bottom of the leg of the pig using a knife, this activity is carried out over only 18 seconds. Whereas the real journey that official work is 8 hours and 30 minutes per day. Therefore, the employee performs this function for 4 hours per day, averaging 25,440 daily movements for this function.

The second function is to remove the bones from the rest of the loin of the pig meat and also use as a tool a knife. This activity is carried out in 16 seconds. Working hours that employee also is 8 hours and 30 
minutes a day running for 4 hours doing this role, he performs an average of 31,440 daily movements.

During the execution of activities employees perform some movements overloading the muscles and tissues of the body, some postures are high-risk health workers (fig. 1), as an example one can cite some postures:

- Shoulder abduction above $45^{\circ}$ which may contribute to the onset of shoulder tendinitis;

- Often leads to ulnar deviation De Quervain's tendonitis, especially when combined with excessive force.

- Cervical spine flexed excessively leads to cervibraquialgia.

- Bending the wrist can often emphasized in flexor tenosynovitis, average pressure in the carpal tunnel and medial epicondylitis.

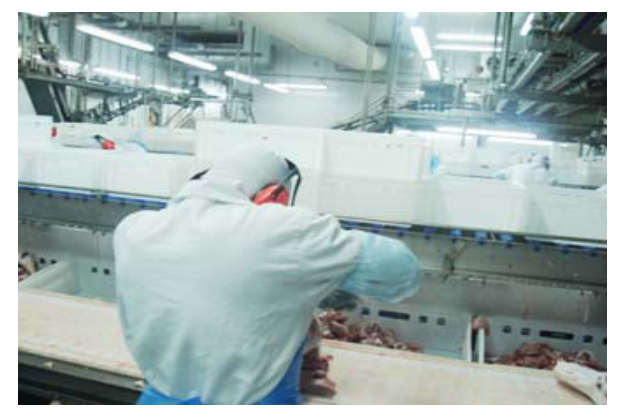

Figure 1: Collaborating with shoulder abducted.

Cervicobraquiais pains can be produced by organic and functional disorders caused by repetitive work and the increase in static muscle loading which, in turn, may be due to awkward postures or repetitive movement for long periods without adequate rest. Physical examination may show changes in range of motion of the neck, trapezius spasm and the presence of "trigger points", whose block with lidocaine produces pain relief.

The criterion for repeatability was proposed, suggesting that any duty cycle of length less than 30 seconds would be highly repetitive. Another important factor in relation to the repeatability is evidenced by empirical findings that the injuries usually occur when a repetitive task is carried out throughout the day. That is, tasks performed most of the day usually do not bring injury.

In Bones of the Leg currently have the following situation to slaughter 4,200 pigs. Table 1 exemplify the control data for the activity of the Leg Bones. In this table we have described three main activities designated as $\mathrm{A}, \mathrm{B}$ and $\mathrm{C}$ being.

The withdrawal of anqueta (Activity A) has an average value of $0.389 \mathrm{~s}$ or 23.34 seconds in the sexagesimal scale. An important point for this is that the activity has a cycle less than 30 seconds. For Activity B) Make the first cut and remove the muscle have a mean value of $0.397 \mathrm{~s}$ or 23.82 seconds also less than 30 seconds. And finally in activity C) femur bone we remove 0.293 seconds or 17.58 seconds. With these data it is possible to determine the units produced per man hour in accordance with Table 2.

To compare the scaling of the production line with the manpower needed to perform these activities created to Table 3 for the Bones of the Leg. In this table the UPHH Real is what the employee produces definitely because of the constant speed line, ie, there is a constraint to follow the pace of production determined.

Assessed in the workplace was found that the noise is continuous, using a dosimeter to measure the noise to which employees are exposed within the industry, the values shown in Fig. 2.

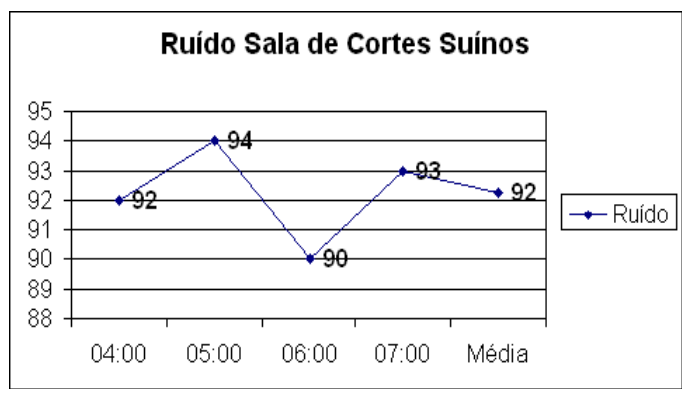

Figure 2: Noise levels in the cutting room.

According to Ordinance No. 3751 of 23/11/1990 of the Ministry of Labour and Employment is not permitted exposure to noise levels above $115 \mathrm{~dB}(\mathrm{~A})$ for individuals who are not adequately protected. The loud noise above $90 \mathrm{~dB}$, prevents verbal communication. People need to speak louder and pay more attention to be understood. This all adds to the psychological stress and the level of attention. 
Table 1

Time standards for the performance of the leg bones

\begin{tabular}{|l|l|l|l|l|l|l|l|l|l|l|l|}
\hline Activity & $1^{\mathrm{a}}$ & $2^{\mathrm{a}}$ & $3^{\mathrm{a}}$ & $4^{\mathrm{a}}$ & $5^{\mathrm{a}}$ & $6^{\mathrm{a}}$ & $7^{\mathrm{a}}$ & $8^{\mathrm{a}}$ & $9^{\mathrm{a}}$ & $10^{\mathrm{a}}$ & Mean \\
\hline A & 0,410 & 0,363 & 0,358 & 0,536 & 0,422 & 0,365 & 0,347 & 0,341 & 0,404 & 0,342 & 0,389 \\
\hline B & 0,384 & 0,503 & 0,380 & 0,489 & 0,276 & 0,279 & 0,361 & 0,494 & 0,311 & 0,490 & 0,397 \\
\hline C & 0,288 & 0,234 & 0,267 & 0,233 & 0,239 & 0,301 & 0,377 & 0,281 & 0,323 & 0,384 & 0,293 \\
\hline
\end{tabular}

Table 2

Determination of units produced per man-hour in the leg bones

\begin{tabular}{|l|l|l|l|l|l|l|l|}
\hline Activity & Rhythm & Parts & Description & $\begin{array}{l}\text { Weight } \\
(\mathrm{kg})\end{array}$ & Concessions & $\begin{array}{l}\text { UPHH } \\
(\text { Parts/Hh })\end{array}$ & $\begin{array}{l}\text { UPHH } \\
(\mathrm{Kg} / \mathrm{Hh})\end{array}$ \\
\hline A & $100 \%$ & 1 & Gammon & 6,408 & $11,64 \%$ & 138,23 & 885,77 \\
\hline B & $100 \%$ & 1 & Gammon & 6,408 & $11,64 \%$ & 135,47 & 868,09 \\
\hline C & $100 \%$ & 1 & Gammon & 6,408 & $11,64 \%$ & 183,62 & $1.176,63$ \\
\hline
\end{tabular}

Table 3

Comparison between the data sizing Hand-to-Work and the reality of the Leg Bones.

\begin{tabular}{|l|l|l|l|l|l|l|}
\hline Activity & $\begin{array}{l}\mathrm{N}^{\mathrm{o}} \\
\text { Employees } \\
\text { Authorized }\end{array}$ & $\begin{array}{l}\mathrm{N}^{\mathrm{o}} \\
\text { Employees } \\
\text { Required }\end{array}$ & $\begin{array}{l}\text { Shift } \\
(\mathrm{h})\end{array}$ & $\begin{array}{l}\text { UPHH } \\
\text { Real } \\
(\text { Peças/Hh) }\end{array}$ & $\begin{array}{l}\text { UPHH } \\
\text { Real } \\
(\mathrm{Kg} / \mathrm{Hh})\end{array}$ & Productivity \\
\hline A & 4 & 3,40 & 8,80 & 126,50 & 810,612 & $85,00 \%$ \\
\hline B & 4 & 3,47 & 8,80 & 126,50 & 810,612 & $86,75 \%$ \\
\hline C & 4 & 2,56 & 8,80 & 126,50 & 810,612 & $64,00 \%$ \\
\hline
\end{tabular}

In the survey of the lighting industry has been found that lux is 350 lux. For work in industry is recommended between 200-600 lux, thus preventing muscle fatigue and at the same time have a higher yield during the workday.

The temperature of the room where pork cuts work on average 250 employees, is $12^{\circ} \mathrm{C}$. To [2], cold below $15^{\circ} \mathrm{C}$ reduces the concentration and reduces the capacity to think and judge. It also affects muscle control, reducing some motor skills and dexterity and strength. If the cold affect the entire body, the overall performance may be affected due to tremors. Therefore, employees use the type hooded jackets during their activities within the sector.

\section{Conclusion}

Ergonomic Assessment of Work in activity analyzed in this study, it was found that the positions taken in carrying out activities in general cause mus cle overload on employees, especially in the shoulders and wrists.

It was observed that for a few moments, the employees work with the shoulder abducted anglegreater than $45^{\circ}$ and the fiber medium deltoid are tensioned all the time, and cause compression of the fibers of the supraspinatus the acromion to carry out the abduction arm.

In relation to the handle, the employee is constantly producing ulnar deviation and the overuse of this joint may result in inflammation of the tendons of the thumb.

With constant repetition of movements that occurs during activities, the more likely to suffer the same injuries to the upper limbs. Even with job rotation, employees perform repetitive movements with other functions, but with fewer of these movements. The environmental risks such as noise and lighting do not affect workers' health, analyzed the activity for which the indices are found within the sector within the governing legislation. In addition, employees use Personal Protective Equipment, mitigating the risks.

Temperature evident within the sector, below $15^{\circ}$ $\mathrm{C}$, decreases concentration and reduces the capacity 
to think and judge. It also affects muscle control, reducing some motor skills and dexterity and strength. Therefore, the employees use special clothes to mitigate the effects of low temperature. The organization of the workplace is presented within the standards established by the Ergonomic NR17 (Norm 17), anthropometric and layout issues are presented propriately within this industry sector assessed, making the activity less harmful to health of employees.

Overall breaks offered to employees in the form of concessions to alleviate losses caused by excessive workload and repeatability of movements.

With regard to productivity, all functions are below the recommended ie the acceptable range is 90 to $110 \%$. It has functions with very low productivity even as the withdrawal of the femur bone with $64 \%$ and $66 \%$ Descourear Palette.
With regard to productivity, all functions are below the recommended ie the acceptable range is 90 to $110 \%$. It has functions with very low productivity even as the withdrawal of the femur bone with $64 \%$ and $66 \%$ Descourear Palette.

\section{References}

[1] Couto, H. A. Como Implantar Ergonomia na Empresa: A Prática dos Comitês de Ergonomia Belo Horizonte: Ergo, 2002, $336 \mathrm{p}$.

[2] Iida, I. Ergonomia Projeto e Produção. São Paulo, Editora Edgard Blücher LTDA, 2003. 9 $9^{\mathrm{a}}$ reimpressão. 